\title{
Uma historiografia da modernidade educacional
}

A historiography of the educational modernity

André Luiz Paulilo

O balanço que foi feito recentemente da produção historiográfica da educação brasileira (Warde, 1984; Bontempi Jr., 1995; Alves, 1998; Catani; Faria Filho, 2002; Vidal et. al. 2005) chama a atenção para a permanência, nas últimas três décadas, de temas e períodos relacionados ao movimento da Escola Nova. Os estudos sobre a Primeira República, as ideias escolanovistas e o movimento educacional brasileiro nos anos 20 e 30, as políticas educacionais e as reformas dos sistemas escolares no início do século passado ainda estão presentes nos programas de pós-graduação (Warde, 1984; Bontempi Jr., 1995), nos diversos congressos da área (Nunes, 1996; Alves, 1998; Xavier, 2001) e no GT História da Educação da Associação Nacional de Pesquisa e Pós-Graduação em Educação - ANPed (Catani; Faria Filho, 2002; Vidal et. al., 2005).

André Luiz Paulilo é professor da Universidade Municipal de São Caetano do Sul, Brasil, e pesquisador do Núcleo Interdisciplinar de Estudos e Pesquisa em História da Educação da Universidade de São Paulo (NIEPHE-USP).

Artigo recebido em 22 de novembro de 2009 e aprovado para publicação em 5 de março de 2010.

Est. Hist., Rio de faneiro, vol. 23, $n^{o}$ 45, p. 27-49, janeiro-junho de 2010. 


\section{André Luiz Paulilo}

No entanto, atualmente, à abordagem centrada na oferta de ideias do período, no debate educacional e nas ações que consubstanciaram pensamentos em políticas educacionais acrescentam-se estudos de trajetória, da materialidade escolar, da circulação e apropriação dos impressos, dos tempos e espaços da escolarização. Embora breves e sem terem a intenção de esgotar o tema, os mapas elaborados sobre a produção em História da Educação implicam o reconhecimento de que as perspectivas da pesquisa sobre a Escola Nova têm mudado nas últimas décadas.

Conforme Vidal e Faria Filho (2005: 117) advertem, agora, temas como pensamento e ideias pedagógicas e organização escolar "podem estar sendo analisados com base em perspectivas diferentes daquelas observadas nos anos de 1970 e 1980". Em muitos sentidos, o movimento educacional brasileiro que se constituiu em torno do Manifesto dos Pioneiros da Educação Nova foi um objeto de pesquisa inteiramente recriado durante o contínuo processo de pesquisa das últimas três décadas. Clarice Nunes (1992: 152) mostrou isso com precisão, quando propôs que o novo repertório de questões da historiografia teria operado um deslocamento de enfoque dos modelos dominantes de educação, como a Escola Nova, para "as múltiplas e diferenciadas práticas de apropriação desses modelos". Segundo Nunes (1992: 152), a ênfase desta historiografia recai sobre "os usos diversos que os agentes escolares fazem da própria instituição escolar, sobre a prática de apropriação de práticas não escolares no espaço escolar e os múltiplos usos não escolares dos saberes pedagógicos".

No artigo "História da educação brasileira: novas abordagens de velhos objetos" e, em colaboração com Marta Carvalho, no ensaio "Historiografia da educação e fontes", Nunes $(1992 ; 1993)$ detalha os meios pelos quais se deu a renovação das abordagens desse velho objeto de preocupação da historiografia. De acordo com suas reflexões, a crítica das matrizes interpretativas cristalizadas, a ampliação das fontes de pesquisa e a reconstrução das categorias analíticas não só permitiram transformar em problema o que era tomado como fato estabelecido, como também alteraram os modelos de compreensão que tornam as pesquisas acerca da história da reconstrução da escola pública no Brasil relevantes e consistentes. O abandono dos grandes recortes temáticos e "a opção por análises pontuais, delimitadas e tão exaustivas quanto possível, da particularidade das práticas e dos produtos culturais investigados" (Carvalho; Nunes, 1993: 37) se fizeram sentir nos resultados dos estudos sobre a educação dos anos 20 e 30. Passar a levar em consideração, por exemplo, a cidade (Monarcha, 1989; Nunes, 1993; 1996; 1998), a materialidade (Vidal, 2001), os tempos e os espaços escolares (Silva, 2004), a diferenciação social dos papéis sexuais na educação (Vidal, 1996; 1998; Rodrigues, 2002) e noções como circulação e apropriação, saberes pedagógicos e cultura escolar não foi pequena transformação. 
Não obstante o impacto da nova história cultural francesa sobre a recente historiografia da educação brasileira, a reavaliação do movimento educacional brasileiro convive com permanências consagradas pelas escritas históricas do campo. Para Bontempi Jr. (1998: 92), a escolha maciça desse período para estudo até fins dos anos 1980 implicava o "reconhecimento de que o pensamento educacional brasileiro se sistematiza justamente quando o Estado Nacional se consolida, o que é uma aceitação distraída das próprias teses dos pioneiros". Amplamente retomada na historiografia da educação, a versão da chamada geração dos pioneiros da educação nova sobre a importância e o caráter da sua própria prática político-pedagógica perdeu terreno desde as críticas publicadas entre $1986 \mathrm{e}$ 1989 por Marta Carvalho ao discurso apologético de Fernando de Azevedo em $A$ cultura brasileira acerca do movimento educacional dos anos 20 . A rígida demarcação do terreno do consenso e do perigoso pela narrativa de Azevedo sobre a configuração dos objetos de investigação da historiografia da educação esgarçou-se, mesmo que, como explica Bruno Bontempi (1999: 98), permaneça sendo uma herança contundente. Embora, ou mesmo porque, muitas das representações que os renovadores da educação instituíram como memória tenham sido desarticuladas e criticadas, ainda é o caso de se perguntar sobre o sentido das permanências, das apropriações das "teses dos pioneiros" nos atuais estudos sobre a Escola Nova.

O emprego dos termos moderno e modernidade para discutir as reformas da instrução pública nos anos entre 1920 e 1935 é um exemplo dessas apropriações. Não escapou a ninguém que investigou o período a ambição do escolanovismo dos pioneiros de promover uma nova civilização por meio de uma nova educação. A interpretação, no entanto, remonta aos próprios pioneiros, sendo Fernando de Azevedo, conforme aponta Carvalho (1999: 25), aquele que mais recorrentemente fez uso da expressão educação nova como estratégia de demarcação de posições. Repetidas vezes, abordagens específicas sobre a Escola Nova e o movimento educacional entre a Primeira República e o Estado Novo foram criticados por deixarem de considerar procedimentos de crítica bibliográfica e documental para escapar do enquadramento imposto pelas interpretações de Fernando de Azevedo (cf. Carvalho, 1988; 1989). Ousadas à época, essas críticas incorporaram-se ao atual fazer historiográfico de modo que, hoje, as pesquisas a respeito das reformas da instrução pública oferecem oportunas reflexões sobre a relação problemática entre história e memória do movimento educacional brasileiro dos anos 20. Apesar disso, ainda se recorre aos termos moderno e modernidade para análise das mudanças ocorridas na educação entre 1920 e 1935.

As circunstâncias como isso tem sido feito é a preocupação central deste artigo. Trata-se de compreender a tendência da historiografia ainda se servir das ideias associadas ao moderno para fazer referência à tentativa escolanovista de 


\section{André Luiz Paulilo}

afirmar uma ruptura radical com a tradição educacional do país. Mais ao modo de um estudo de caso do que propriamente um inventário dos sentidos atribuídos ao movimento educacional brasileiro das décadas de 20 e 30, procuro abordar a modernidade da Escola Nova na produção historiográfica a respeito da reforma do ensino dirigida por Fernando de Azevedo no Distrito Federal entre 1927 e 1930. O que vai ser apresentado aqui é o estudo sistematizado de uma historiografia específica, cujas análises passam, em alguma medida, por uma discussão acerca do novo e do moderno na chamada reforma Fernando de Azevedo. Isso implica sugerir comparações e contrastes a respeito do modo como as pesquisas de história da educação se debruçaram sobre o período dos anos 20 e 30 depois que se deixou de considerá-lo marco inaugural da educação pública no país e da construção da ideia do Brasil republicano (cf. Xavier, 2001: 224).

Em muitos sentidos, o esforço empreendido aqui busca tecer considerações sobre o estudo da mudança que atualmente as análises a respeito da Escola Nova propõem.

\section{O novo e o moderno na historiografia do movimento educacional dos anos 20}

Entre as muitas análises fundamentais acerca do advento reformista dos anos 20-30 há uma série de estudos em que se conceituou de moderna a proposta educacional dos pioneiros e as suas práticas de organização escolar do sistema público de ensino. Para Libânia Nacif Xavier (1999: 37), o artigo de Jorge Nagle (1977) "A educação na Primeira República" é fundador desse tipo de abordagem. Segundo mostrou a autora, a partir dele as diversas pesquisas que se debruçaram sobre os anos 20 "assinalaram como marco relevante desse período a ideia de fazer da educação a bandeira de um país moderno". Nessa direção, o escolanovismo no Brasil e o movimento reformador que lhe prepara o terreno foram estudados paradigmáticos da modernidade dos anos 20: orientação tanto mais progressista quanto mais técnica.

Para compreender as mudanças no sistema escolar brasileiro nos anos 20, Jorge Nagle (1977: 264) analisou o que chamou de otimismo pedagógico, caracterizando-o "pela crença nas virtudes de novos modelos". Do modo como entendeu Nagle, nesse momento da ampliação da rede e da clientela escolares no Brasil, já "não importa muito qualquer esforço para difundir a escola, pois o que mais importa é difundir a escola que reproduz um novo modelo". Assim, as ideias da Escola Nova pareceram-lhe ser a forma mais acabada do otimismo pedagógico. Pretendendo deslocar o educando para o centro das reflexões educativas, o 
escolanovismo visou alterar os padrões em que se sustentava a chamada "escola tradicional" e, portanto, substituir um certo modelo pedagógico. A obra de Nagle $(1974 ; 1977)$ sugere que, por meio dos movimentos reformistas estaduais das escolas primárias e normais, o otimismo pedagógico operou a tecnificação do campo educacional. Fundamentalmente, Nagle (1974: 101-102) propõe que os temas da escolarização vão se restringindo a formulações puramente educacionais ou pedagógicas durante os anos 20. Essa proposição faz parte de uma tese segundo a qual o aparecimento dos educadores profissionais, autênticos técnicos em escolarização, comprime os problemas educacionais num domínio especializado, sem vinculações com questões de outra ordem que não a pedagógica.

Entre os estudos que se basearam nas análises de Nagle, a ideia de substituição de um modelo político de intervenção sobre a educação por um modelo pedagógico apareceu com a maior frequência. Clarice Nunes (1995) deteve-se nos principais exemplos, mostrando como Paiva (1973), Saviani (1983) e Ghiraldelli (1986) operaram com uma matriz explicativa comum: a despolitização das formulações educacionais que gerou o chamado "otimismo pedagógico". Suas críticas a essas posições encaminham-se no sentido de apontar-lhes a estreiteza dos resultados conseguidos:

A tese da tecnificação e o quadro explicativo no qual Nagle a arma reforçou um movimento dual de percepção da realidade: sistema agrário-comercial por sistema urbano-industrial; sociedade fechada $\mathrm{x}$ sociedade aberta; regionalismo $\mathrm{x}$ cosmopolitismo; escola nova $\mathrm{x}$ escola tradicional; entusiasmo pela educação x otimismo pedagógico; perspectiva interna x perspectiva externa; inovação por tradição; políticos $\mathrm{x}$ técnicos. Este movimento tem sua raiz no atrelamento que Nagle faz das modificações ocorridas no campo educacional às mudanças decorrentes da crise do sistema oligárquico e à expansão das atividades industriais, que culminaram numa revolução de caráter democrático-burguês no país (Nunes, 1995: 18).

De acordo com Clarice Nunes, pode-se afirmar em termos mais gerais que a matriz explicativa de Jorge Nagle é a mesma da versão dos protagonistas do movimento educacional à época, homogeneizante e despolitizadora dos debates de então. Essa conclusão é parte de uma perspectiva de análise da historiografia que foi aberta com a crítica da narrativa de Fernando de Azevedo em $A$ cultura brasileira empreendida por Marta Carvalho durante seu doutoramento.

A partir da sua tese Molde nacional e forma cívica, de 1986, e de dois artigos publicados em 1988 e 1989, Carvalho propõe que a pesquisa em História da 


\section{André Luiz Paulilo}

Educação estaria demasiadamente marcada pela narrativa de Azevedo e, assim, referenciada pela memória e pela história construída por um dos principais protagonistas do movimento educacional dos anos 20 e 30. A hipótese se mostrou profícua, alertando acerca da incidência das interpretações de Fernando de Azevedo na historiografia da educação. Acompanhando a crítica realizada por Marta Carvalho, é possível dizer que a oposição novo/velho no uso de Fernando de Azevedo em $A$ cultura brasileira não só despolitiza o movimento educacional como também opera homogeneizações. Por um lado, a oposição entre tradicionalistas e renovadores enquanto categoria descritiva que biparte esse movimento em dois campos antagônicos nos anos 30 é considerada regra de ordenação de um discurso consagrado à memória sobre a então recente história do país. Por outro, indica-se que, na amálgama política que Azevedo faz crer existir no movimento educacional durante os anos 20, medravam correntes de opinião e facções variadas. Nesse aspecto, Marta Carvalho diverge das posições de Azevedo (1943), de Nagle (1974), de Paiva (1973) e de Jamil Cury (1978) quanto ao sentido modernizador das propostas educacionais do período. Segundo suas conclusões, não se tratou de mera assunção do novo, de tecnificação do ensino ou de crítica ao caráter excludente da escola.

Por entre essas vias, Carvalho (1998) não só critica o sentido modernizador atribuído às propostas renovadoras dos anos 20 como também o repensa. Nas suas análises, a ênfase conferida ao projeto civilizador elaborado no interior do movimento educacional sugere que, a exemplo da renovação escolar, a politização do campo educacional se faz, nesses anos, em outros termos que não o desenhado por Fernando de Azevedo em $A$ cultura brasileira. Descrevendo o efeito unificador no que foi considerado por Azevedo como marcha gloriosa e avassaladora do "novo", batendo-se em diversas frentes contra o "velho", o "tradicional" e o "arcaico" no período anterior a 1930, Marta Carvalho (1989: 30) insiste que o movimento educacional nos anos 20 então aparece expurgado de tudo o que nele foi compromisso com a conservação da ordem existente.

Com esse escopo, ela aponta para a possibilidade de considerar a pressão pela abertura de espaço para grupos de técnicos nos governos estaduais na década de 20 indissociável do tipo de atuação dos agentes que prescrevem os recursos técnicos de intervenção social. Nesse contexto, a Associação Brasileira de Educação (ABE) é concebida como uma instância de organização destinada a abrir ou alargar um espaço de ação política desse "técnico" nas elites dirigentes da burocracia. A abordagem de Marta Carvalho $(1986,1988,1989)$ questiona o papel de arautos da crítica do caráter excludente da escola conferido aos renovadores de 20 sediados na ABE pela matriz interpretativa consagrada por Azevedo. Segundo ela, na verdade, procurava-se à época efetivar um projeto particular de sociedade, cujo principal instrumento de conformação dos indivíduos era a educação. 
Conforme fica esclarecido em Molde nacional e forma cívica, nos anos 20 "saúde, moral e trabalho eram os três pilares principais em que se assentava a convicção a respeito da importância da educação" (Carvalho, 1998: 148). A ênfase na educação como "instrumento de controle social", e a percepção das "possibilidades disciplinadoras de práticas", muitas delas moldadas pela incorporação de métodos da chamada moderna pedagogia, acompanham as seguintes linhas. $\mathrm{O}$ discurso que então se produziu avançava por oposições que constituíam, pelo negativo, a importância do movimento educacional. Marta Carvalho (1998: 142) aponta que "pessimismo", "desânimo", "inação", "utilitarismo", "egoísmo", "descrença" foram termos que dramatizavam o mal contra o qual se prescreveu a reação. Principalmente acalentadas no círculo da $\mathrm{ABE}$, "questões de saúde, de moral e relativas à organização do trabalho integravam as expectativas referentes à ação formadora da escola" (Carvalho, 1998: 150). Em muitos sentidos, o projeto cultural dos reformadores sociais sediados na $\mathrm{ABE}$ foi visto por Marta Carvalho como um verdadeiro projeto de transformação civilizatória, perfeitamente consoante às exigências de uma sociedade de formato industrial. As expectativas de modernização e controle social que Marta Carvalho analisa já não são mais as advindas da ampliação das oportunidades de acesso à escola tratadas por Azevedo (1943) e Jamil Cury (1978), mas sim as de uma elite que ideava a escola primária como instrumento de formação do cidadão laborioso, ordeiro e saudável.

Marlos Bessa Mendes da Rocha (2004:135), ao contrário, ressaltou que "não se pode atribuir aos discursos educacionais naqueles anos de 1920 um sentido teleológico configurado na modernização capitalista que se seguiu, ou num processo civilizatório que lhe seria inerente". Segundo a sua compreensão, as configurações discursivas do período não têm, todas elas, o mesmo compromisso com a racionalidade capitalista ou com o domínio autoritário constituído posteriormente. Rocha (2004) rejeita a tese do consenso civilizatório que marcaria a ação política e educacional dos educadores nos anos 20 , entendendo que as suas falas eram dissonantes e apontavam para alternativas político-sociais distintas. Vale-se da crítica à lógica binária, dicotômica na confrontação entre Estado e não-Estado, implícita à análise histórica do pensamento social brasileiro da Primeira República realizada por Bolívar Lamounier para afirmar que os caminhos de modernização então propostos nem sempre foram os mesmos.

Embora discuta a variedade de projetos de modernização que Nóbrega da Cunha, Fernando de Azevedo e Anísio Teixeira expressaram na ABE com certo grau de detalhamento, revela-se preocupado principalmente com a construção desse grupo em um ator educacional. Ao apontar a multiplicidade de modernidades que podem ser pensadas a partir das realizações políticas dos chamados pioneiros da educação nova, o autor argumenta que "um grande trunfo do grupo 


\section{André Luiz Paulilo}

renovador foi ter conseguido forjar laços de identidade e solidariedade entre boa parte dos líderes desses movimentos públicos de reforma escolar, galvanizando para o novo ator o prestígio social conquistado por essas lideranças" (Rocha, 2004: 173). Sua explicação concentra-se na transitividade dos atores, do espaço estratégico da política e do conjunto da ordem social que faz da modernidade "mais que uma simples linha reta, que transforma o tradicional em moderno" (Rocha, 2004: 189), a expressão dos matizes das mudanças ocorridas à época em setores tão diversos quanto o produtivo e o educacional.

Em seus principais artigos sobre a escola no primeiro quartel do século passado, Clarice Nunes $(1992,1994,1996)$ também insistiu no movimento contraditório de gestação do moderno no país. Na sua análise da impregnação que há da cultura urbana no espaço escolar, ela rejeita a prática explicativa do espelhamento do modelo paulista de cidade sobre outras cidades brasileiras. O reconhecimento do que foi diverso no Rio de Janeiro em relação a São Paulo no estudo da escola pública carioca estimulou a busca de uma linha de investigação histórica frutífera, apesar de relativamente negligenciada. Ao colocar em foco "os saberes e poderes que foram acionados para construir uma política educativa desdobrada no cotidiano da cidade", Nunes $(1992: 170 ; 1993 ; 1996)$ procurou resgatar as representações do espaço urbano e da própria escola dentro do espaço escolar. Entre as perspectivas que então descortinou para a compreensão do esforço ideologizador de toda uma geração de educadores na capital federal, a abordagem da tensa aproximação entre a escola e a rua e da construção da cidadania e da civilidade nas escolas urbanas abriu discussões interessantes sobre a capacidade do aparelho escolar disciplinar o uso de tempos e espaços então vistos como focos de libertinagem e revolta.

Sobretudo ao tratar do modo como o Rio era percebido no projeto de educação defendido pelas elites cariocas, Nunes (1992: 162) notou que a capital era apresentada como foco de resistência ao amadurecimento capitalista, como a negação do trabalho, do espírito científico e do progresso material. Diferentemente do que ocorreu no modelo urbano paulista, tido como exemplo de cidade que havia sido capaz de superar tradições arcaicas e se homogeneizar culturalmente pela modernização que acompanhou a implantação da indústria e da lógica capitalista de mercado, nas representações acerca da cidade do Rio de Janeiro o mundo da produção ainda não era tão preciso e central. Clarice Nunes (1996:156), que concorda com Marta Carvalho em diversos aspectos, confere outro peso às práticas e valores que não têm na lógica do mercado seu princípio organizador. São destacados os limites da escola em levar "as crianças a interiorizarem e transferirem para a vida cotidiana os hábitos e atitudes que procurava ensinar" (Nunes, 1992: 163). Nessa perspectiva, aborda-se, mais que as dimensões do consenso civilizatório, o campo educacional no interior de "um espaço urbano que estabeleceu com a mo- 
dernidade uma relação peculiar a partir da condição de capital política, da ambição do cosmopolitismo e da convicção de que o discurso da cidade era um discurso metonímico para todo o país" (Nunes, 1996: 156).

\section{A “nova política educacional do Brasil" reconsiderada}

O esforço de compreensão e crítica da memória elaborada pelos "grandes educadores" dos anos 20 e 30 sobre o movimento educacional que protagonizaram envolveu o estudo da chamada Reforma Fernando de Azevedo com questões historiográficas importantes. Tanto o discurso constitutivo do plano de reorganização do ensino carioca quanto a sua construção e modernidade foram rediscutidos em função das preocupações então em curso com o projeto político que a reforma disseminou e com as estratégias das quais se utilizou. De modo que, ainda recentemente, a reforma do ensino promovida por Fernando de Azevedo no Distrito Federal entre 1927 e 1930 serviu para reavaliar as bases em que se promoveu a renovação educacional no país. O recrudescimento da crítica histórica ao legado instituído pelos chamados pioneiros da educação nova abrange uma série de tentativas de se explicar o advento reformista de 1928 na capital por uma perspectiva diferente daquela construída pelos próprios reformadores. Monarcha (1989), Carvalho (2000), Hanna Matte (2002) e Mendes da Rocha (2004) publicaram estudos tratando da ideia de que a reforma Fernando de Azevedo patenteia uma época enfaticamente nova em educação. Variados sobretudo nos métodos e nas conclusões de pesquisa, seus empreendimentos de análise propõem que, na reforma do ensino promovida por Fernando de Azevedo na capital no último quadriênio dos anos 20, os termos "moderno" ou "modernidade" referem-se a processos específicos de organização da escola e da sociedade.

A ênfase conferida por Carlos Monarcha (1989: 104) à pretensão de racionalização do funcionamento das atividades pedagógicas no discurso reformista dos anos 20 e 30 sugere que toda uma comunidade de homens cultos elaborou estratégias não-repressivas de hegemonia social sob o ambíguo rótulo do moderno. Valendo-se, com discrição, das ideias de Edgar de Decca, Monarcha (1989) mostrou como então se procurou consolidar um conjunto doutrinário capaz de criar uma consciência de ruptura. Conforme explicou em $A$ reinvenção $d a$ cidade e da multidão, do mesmo modo que a memória histórica da Revolução de 1930, a memória legada pelos renovadores sobre a Escola Nova levou o investigador a mover-se em torno das teses e dos temas criados pelos próprios vencedores. Para Hilsdorf (2003: 81), a reavaliação que Carlos Monarcha faz do movimento educacional brasileiro desses anos é lapidar ao afirmar que "os escolanovistas são modernos para quem acredita que 1930 é a revolução burguesa”. 


\section{André Luiz Paulilo}

Nesse enquadramento da questão, Fernando de Azevedo é tido por Monarcha (1989: 135) como "facho de luz", produtor de diretrizes gerais: "será Fernando de Azevedo quem explicará as finalidades sociais da escola nova brasileira, no contexto de regeneração moral das 'classes perigosas', procurando elevá-las à altura da missão que o século XX lhe reservara". A interpretação de Monarcha reserva uma atenção específica à atuação de Azevedo na reforma do ensino no Distrito Federal entre 1927 e 1930. Ele propõe que, nesse empreendimento, Azevedo fez o agenciamento liberal para a auto-conservação da sociedade burguesa se passar pela busca do novo, pela substituição de uma concepção de ensino vencida pelo tempo. O enfoque de Monarcha (1989) na orientação ideológica que a reforma da instrução pública da capital federal expressou não só permite observar o alcance das mudanças pretendidas como também o que então se buscou conservar. Mais que as estratégias reformistas, Monarcha (1989: 98) analisa o cuidadoso empenho de construção e preservação da memória do movimento educacional dos anos 20 que Azevedo protagonizou.

A forma como Marta Carvalho (2000: 245-246) analisa o episódio reformista de 1928 na capital federal revela, sobretudo, a contradição que havia entre o apelo modernizador dessa reforma e a velha política a que ela servia:

Nos quadros da disputa oligárquica, especialmente acirrada nesses anos que precederam a Revolução de 1930, capitalizar o apelo modernizador da "causa educacional", promovendo uma reforma de vulto na capital do país, era trunfo político considerável para o situacionismo. Por isso, abrir espaço na capital federal para a intervenção desses mediadores do ensino moderno que eram os profissionais da educação vindos de São Paulo, nos anos 20, era iniciativa especialmente polêmica. Não tinha o Rio os quadros técnicos necessários à Reforma da Instrução Pública? Não era São Paulo um dos principais focos da irradiação do poder das velhas oligarquias no cenário nacional?

A demissão de Azevedo, tão logo estivesse consumada a Revolução de 1930, parece dar razão a essa interpretação. Nesse sentido, a reforma do ensino de 1928 no Distrito Federal pode ser vista como um divisor das posições assumidas no conflito que rachou o movimento educacional imediatamente após a Revolução.

Conforme esclarece Marta Carvalho (2000: 247), o isolamento político imposto a Azevedo nos anos imediatamente posteriores à Revolução de 1930 por sua explícita vinculação à facção oligárquica paulista inimiga de Vargas não impediu que a reforma que empreendera se impusesse no movimento educacional como marco periodizador do movimento de renovação educacional no Brasil. A 
autora considera que, "objetivando concretizar o princípio da escola única centrada no trabalho, a Reforma Fernando de Azevedo fecha um ciclo das reformas da Instrução Pública no Brasil". Entretanto, sugere que a nova política de educação que o governo instalado pela Revolução de 1930 passa a apregoar viu em Azevedo um representante da velha ordem (Carvalho, 2000: 247).

A crítica de Mendes da Rocha à Marta Carvalho - tendo por base o arrazoado de que as dimensões do consenso civilizatório que marcaria a ação política e educacional dos educadores profissionais possuem um sentido teleológico, configurado na modernização capitalista que se seguiu - abrange a história das ideias políticas. Assim, ao contrário de Marta Carvalho, Mendes da Rocha atribui à reforma de 1928 o rompimento com a prática política situacionista, apresentando-a como uma ponte entre as ideias políticas da dissidência do Partido Republicano Paulista com as de uma geração de críticos nascida com a República. Desse ponto de vista, a ação de Fernando de Azevedo na Diretoria de Instrução pareceu-lhe ser tanto uma proposição com princípios enunciados claramente, dirigidos a um meio social específico e que tomou a sua incorporação e participação como condição para a solução do problema que se propunha, quanto uma inovação introduzida em contraposição ao primeiro modelo republicano.

Durante a reforma do ensino carioca, as ideias de extensão do ensino a todo público escolarizável, da integração dos níveis de ensino e da inserção comunitária da escola se consolidaram, do mesmo modo que a crítica ao êxodo rural, a contraposição à cultura verborrágica e o compromisso com o progresso modernizador das relações de trabalho. Assim, segundo a hipótese de Mendes da Rocha (2004: 112-113), na reforma educacional empreendida por Fernando de Azevedo no Distrito Federal entre 1927 e 1930 "se forjou a junção do criticismo republicano paulista com o da geração dos críticos republicanos, cujo perfil territorial era, até então, acentuadamente, carioca e fluminense”.

A questão principal discutida por Mendes da Rocha diz respeito ao novo ideário que a reforma de Fernando de Azevedo expressou. Buscou-se, sobretudo, explicitar os caminhos e ações desse movimento de renovação pela virtude dos conceitos que então se elaboraram para justificar e legitimar inovações no âmbito escolar. Na ênfase dada aos traços específicos do advento reformista do ensino da capital federal entre 1927 e 1930, Mendes da Rocha (2004: 125) argumenta que houve mudanças em três frentes: no quadro ideológico, no paradigma pedagógico e na concepção de progresso. O termo modernidade foi utilizado aqui sobretudo para definir uma ruptura radical com a tradição. Diferentemente de Monarcha e Marta Carvalho, Mendes da Rocha (2004) propõe que as formulações de Azevedo sobre a educação e a sociedade rompem tanto com o velho paradigma republicano da insuficiência do povo quanto com a vertente produtivista 


\section{André Luiz Paulilo}

de um pensamento social propenso a considerar a produção como dimensão necessariamente positiva do desenvolvimento.

Essas discussões sobre a modernidade da reforma Fernando de Azevedo mostram que seu impacto vem sendo reinterpretado, destacando-se a crítica da história-memória do movimento educacional brasileiro e a busca dos seus matizes. Nesse sentido é que se pontua que uma reforma educativa não deve ser pensada como restrita a uma súbita e original transformação pedagógica, devendo ser analisada de forma processual e em íntima conexão com as tensões que estabelece na sociedade (cf. Prost, 1996). Em vinculação com esse tipo de análise, cresceu o interesse pela pesquisa das dimensões produtoras da legitimidade das reformas educativas. Um estudo especialmente atento a essa questão nos anos 20 e 30 é o de Cecília Hanna Mate (2002) a respeito da política do discurso vitorioso que se observa nos escritos de Fernando de Azevedo. Numa direção já aberta por Carvalho (1986) e Monarcha (1989), quando analisaram a memória legada pelos "pioneiros da educação nova", ela reconhece, no discurso da renovação escolar da capital federal, o silêncio em relação às disputas geradas em torno da reforma antes de seguir as pistas sobre a concepção, organização e administração do sistema escolar carioca, deixadas pelas memórias e pelos depoimentos dos reformadores do ensino. Nesse sentido, a contribuição central do ensaio de Hanna Mate foi mostrar a dita modernidade da reforma Fernando de Azevedo como um dos componentes do discurso produtor de verdade em educação.

A abordagem da questão por Hanna Mate (2002: 60) enfoca o discurso utilizado por Fernando de Azevedo enquanto elemento constitutivo da construção da reforma de ensino do Distrito Federal. Assim, uma característica fundamental da sua discussão é o viés proposto. O conjunto dos discursos de Fernando de Azevedo é interpretado mais enquanto tentativa de construção de novas relações sociais através da escolarização do que como indício de novos modos de organização e práticas escolares. Fundamentalmente, Hanna Mate (2002: 63) esclarece que, ao valorizar algumas práticas e negar outras, a Diretoria de Instrução do Distrito Federal apresentou uma proposta de reforma educativa capaz de entremear projetos e programas já postos por outros discursos de educadores envolvidos com as reformas do ensino no país. A autora percebe o advento reformista de 1928 como parte do que se vinha construindo ao longo de intervenções individuais dos profissionais da educação ou de grupos atuantes em diferentes lugares do Brasil. Nesse sentido, a gestão Fernando de Azevedo foi uma entre tantas outras ocasiões em que se cruzaram diversas "propostas e pontos de vista sobre educação e mudança social" (Mate, 2002: 64).

Ainda que atenta para a dimensão nacional das ideias de Azevedo sobre educação, Hanna Mate analisa os contornos próprios da reforma de 1928 na ci- 
dade do Rio de Janeiro. Assim, em meio aos discursos pedagógicos acerca dos problemas sociais dos aglomerados urbanos, Hanna Mate (2002: 67-68) distingue, no contexto das lutas para ordenar e regular experiências, o uso de práticas e de dispositivos de intervenção e controle do funcionamento escolar. Ela propõe que o recenseamento escolar, o cinema educativo e a organização de uma biblioteca e de um periódico de educação foram instrumentos de fabricação de consensos. No caso do censo de 1927, sugere que essa prática conferia respaldo ao poder de decidir (cf. Mate, 2002: 68). Em relação ao cinema educativo, a construção do consenso se daria no âmbito da moral e dos costumes por meio de intervenções no sentido de direcionar o conteúdo das projeções cinematográficas como recurso educativo. Quanto à publicação de livros e periódicos, tratava-se de legitimar novas ideias (cf. Mate, 2002: 75).

Em qualquer uma dessas formas de produção do consenso, recriava-se um conceito sobre educação escolar e seu papel. Segundo Hanna Mate (2002: 76), a dita modernidade das medidas tomadas e intervenções feitas nos espaços de educação através da adoção de técnicas mais eficientes foi resultado de um imaginário social no qual "alguns eram heróis, ao enfrentar o atraso e impulsionar o país para a modernidade, enquanto outros obstruíam a história impedindo seu avanço". A prática do censo escolar, o cinema educativo e as estratégias editoriais foram os elementos centrais, constitutivos dessa dicotomia.

\section{Mudanças no âmbito dos estudos sobre a reforma educativa de 1928}

As discussões sobre a modernidade da reforma Fernando de Azevedo têm sido ampliadas à medida que aumentou a preocupação dos historiadores com o equipamento escolar. Vários estudos recentes voltaram a dar atenção para o solapamento dos principais cânones pedagógicos até a segunda metade da década de 1920, representados como portadores do novo e do moderno. Entretanto, mais que no trato das questões técnicas e políticas postas no processo de institucionalização da escola ou das mutações teóricas e doutrinárias produzidas no campo educativo, esses estudos vêm investindo na análise das estratégias de escolarização do social que o episódio reformista de 1928 acompanhou.

Alguns dos estudos desenvolvidos por Diana Vidal $(1994 ; 1996 ; 1998)$ e por ela orientados no âmbito do Núcleo Interdisciplinar de Estudos e Pesquisas em História da Educação da Universidade de São Paulo (NIEPHE-USP) seguem essa perspectiva. Seus ensaios sobre a educação doméstica e a arquitetura escolar implantadas com a reforma Fernando de Azevedo abriram caminho para monografias focadas especialmente nas relações entre a escola e diversas das instituições sociais à época. A dissertação de mestrado de Rosane Nunes Rodrigues 


\section{André Luiz Paulilo}

(2002), Representações de feminino e educação doméstica, trata da escolarização dos saberes domésticos nas escolas e institutos profissionais femininas no Rio de Janeiro dos anos 20 e 30 . A fotografia além da ilustração (2002), de Rachel Abdala, estuda o uso do recurso da imagem na reforma Fernando de Azevedo. Ambas as dissertações oferecem uma compreensão das formas de articulação da reforma do ensino com as mudanças ocorridas nos costumes e nas artes, reenviando a análise do movimento educacional no período ao tema do moderno e da modernidade.

Rodrigues (2002; 2004; 2008) lançou mão dos estudos de gênero, de Joan Scott a Guacira Lopes, diante do minucioso exercício de professoras, diretoras e alunas, realizado no espaço escolar, com o objetivo de tornar as mulheres competentes no fazer doméstico. As conclusões de sua pesquisa mostram que essa competência foi legitimada e reafirmada por outros sujeitos e em outros espaços sociais, servindo, inclusive, de contraponto para a "futilidade" e a circulação das mulheres nos espaços públicos de lazer. Centrada na ideia de representação, sua dissertação alcança a multiplicidade de entendimentos sobre a mulher e o feminino vigentes nos anos 20 e 30 do século passado. Rodrigues (2002) foi suficientemente sensível às várias formas de atuação social realizadas pelas mulheres cariocas para compreender que foi preciso que a escola se apropriasse dos discursos sobre a mulher produzidos fora do espaço escolar para construir determinadas representações de feminino. Num período de luta feminista pela independência econômica das mulheres e pela regulamentação do trabalho feminino, e também de organização do trabalho conforme as regras da ciência e os objetivos da racionalização no planejamento e desenvolvimento das atividades do trabalho, a educação profissional feminina escolar contrapunha à dona-de-casa tradicional a profissional doméstica, "útil, trabalhadora e capaz de produzir primorosos trabalhos manuais" (Rodrigues, 2008: 75).

Da mesma forma, os estudos da construção das imagens da reforma Fernando de Azevedo no Distrito Federal escritos por Rachel Duarte Abdala (2002; 2008) destacam o tipo e o rumo de uma mudança que se refletiu nas questões do ensino público. O registro fotográfico dos prédios escolares em construção no Distrito Federal entre 1929 e 1930 é visto como uma linguagem constitutiva de uma ordem discursiva própria. Abdala (2002) desenvolveu a ideia de que a fotografia foi um meio utilizado pela Diretoria Geral de Instrução Pública para decidir e disponibilizar o que se devia ver e aquilo em que se deveria crer sobre a nova política de edificações escolares da municipalidade. Assim, como um recurso de linguagem na construção de uma representação singular, a fotografia foi também pensada enquanto ícone da modernidade, na medida em que podia influenciar esteticamente a percepção do empreendimento. Por meio da análise das fotografias produzidas por Nicolas Alagemovits acerca dos novos conjuntos arquitetô- 
nicos das escolas públicas, Rachel Abdala (2002; 2008: 101-103) mostra que o espaço foi "percebido e incorporado como elemento compositivo da representação e da expressão fotográfica" e que a política de edificações de Azevedo procurou na "emoção estética provocada pela confluência da sensibilidade do fotógrafo e dos recursos por ele utilizados" a sua legitimação. Nesse sentido, a reforma Fernando de Azevedo é tratada através da modernidade da sua divulgação. Ademais, Abdala (2002) ressalta o papel privilegiado concedido nos meios de comunicação então utilizados à imagem, à luz e à visibilidade dos edifícios fotografados por Nicolas.

Ainda considerando as monografias dedicadas ao estudo de aspectos das mudanças ocorridas na vida social e cultural do Rio que se refletiram nas questões do ensino público, a abordagem de José Cláudio Sooma Silva (2004) sobre a distribuição do tempo escolar promovido pela reforma do ensino de 1928 é outra contribuição relevante elaborada a partir do NIEPHE-USP. Ao tratar da relação escola e cidade, Sooma Silva $(2004 ; 2008)$ tem procurado dimensionar o impacto da organização do tempo escolar na vida social. Seu foco de análise é a regulamentação do horário de ensino escolar e a cadeia de ações e reações que ela provoca na rotina da casa, do comércio, do transporte, da cidade, enfim. A questão da maneira da população se relacionar com os espaços e os tempos da capital federal após a vaga de remodelação urbana dos anos 10 emerge com força no exame das iniciativas de reforma da cidade e da escola nos anos 20.

As relações que Sooma Silva (2004) tece entre os planos de remodelação urbana e a reforma do ensino público deixa perceber, principalmente, a nova orquestração administrativa para modernizar a cidade-capital. A prefeitura de Antônio Prado Jr. valeu-se do urbanismo e da educação como trunfo político da sua gestão através da contratação de Alfred Agache e do apoio a Fernando de Azevedo. Conforme entendeu Sooma Silva (2004: 162), tanto a reestruturação do ensino como o programa de urbanismo foram tentativas de instituir a ordem e a disciplina no cotidiano da cidade. Às conhecidas interpretações que têm procurado tratar dos projetos de remodelação do Rio de Janeiro, Sooma Silva $(2004$; 2008) acrescenta que nos anos 20 o controle institucional dos tempos do fluxo urbano e da demanda escolar foi o indício de um novo surto de modernização da cidade.

A ênfase que essa série de estudos confere às estratégias de incorporação dos progressos mais recentes da agência humana no empreendimento que Azevedo quis implementar na capital federal consolida uma tendência que já vinha se definindo nos anos 1990. Trata-se de investigações que se ocuparam da reforma do ensino de 1928 para explorar aspectos muito precisos da história da institucionalização escolar e do campo educacional no Brasil. No conjunto das pesquisas que abordam a arquitetura das escolas construídas no Rio entre 1928 e 1930 tem-se um exemplo do quanto a discussão a respeito de uma especificidade 


\section{André Luiz Paulilo}

da reforma do ensino pode contribuir para a compreensão do modelo educativo que então se procurava materializar. Beatriz Santos de Oliveira (1991) e Diana Vidal (1994) desenvolveram a ideia de que a arquitetura escolar desempenhou a função de imprimir visibilidade à reforma. Sublinharam, particularmente, a articulação das dimensões funcionais e estéticas da política de edificações escolares implementada por Fernando de Azevedo, entendendo a adoção do estilo neocolonial como meio de definir valores que moldariam a sensibilidade estética da sociedade daquele período.

Segundo Oliveira (1991), para os anseios reformistas da época, a concepção arquitetônica das novas escolas públicas foi um meio de arbitrar sobre uma tradição. Na sua dissertação Modernidade oficial: a arquitetura das escolas públicas do Distrito Federal, Oliveira (1991: 85) mostra que o estilo neocolonial tornava visível uma modernidade de signo regressivo, denotando ambições liberais sob a forma de retorno às tradições nacionais. Vidal (1994) também argumenta que a adoção do estilo neocolonial na construção dos prédios escolares materializava concepções, conceitos e intenções. Para ela, o neocolonial não só servia como exemplo de nacionalidade como "cumpria a função de criar a imagem de ruptura com as práticas educativas passadas, sendo portador do signo da renovação" (Vidal, 1994: 42).

Do mesmo modo, das pesquisas acerca da formação docente no período da reforma derivam discussões a respeito dos ideais e dos aspectos da renovação educacional no Brasil. Ao estudar a história da formação do professor primário no Distrito Federal, Liéte Accácio (1993: 87) observa, nas recomendações do Programa da Escola Normal de 1929, as novas ideias educativas, os novos métodos de ensino e o "desejo dos reformadores de abrir caminho para o conhecimento da vasta bibliografia pedagógica norte-americana pelos novos professores". Ela enfoca o papel da Escola Normal na reforma Fernando de Azevedo, sobretudo enquanto divulgadora de novos princípios educacionais. A ênfase no estudo dos concursos para professores do ensino normal mostrou-se profícuo para o entendimento da constituição de um campo específico da atuação do magistério. Para Accácio (1993: 137; 2004: 128), a reforma dos programas e os concursos para provimento dos quadros do magistério da Escola Normal parecem representar pontos relevantes da construção da profissão docente e ao movimento de modernização do ensino e da educação brasileira.

O mesmo raciocínio está presente nas conclusões de pesquisa de Vidal (2001) e de Lopes (2006). As iniciativas de reestruturação da Escola Normal e do seu quadro curricular no Distrito Federal, implantadas pela reforma Fernando de Azevedo, são vistas como uma das faces da modernidade organizacional que se pretendia realizar. A exemplo de Accácio (1993), Vidal (2001) e Lopes (2006) perceberam a sintonia dos enunciados que indicavam racionalidade e ciência 
como princípios de ação educativa com os modernos anseios sociais, debruçando-se sobre a história da formação de professores na capital federal entre os anos 20 e 30 .

Outra perspectiva de análise em que o termo modernidade confere sentido ao advento reformista de 1928 na capital federal é a da história política da educação. Uma formulação especialmente perspicaz sobre o conflito entre projetos políticos de reforma educacional e constrangimentos burocráticos que se consolidou com os movimentos educacionais dos anos 20 foi apresentada por Helena Bomeny (1984: 265; 1993: 34-35) quando discutiu o esvaziamento da paixão e da ambição de seus atores perante à estrutura unicista e regulamentar da burocracia do Estado na década seguinte. Ao estudar a atuação pública dos educadores no projeto de edificação da nação brasileira, Bomeny mostra como aqueles que então falavam pela ciência por meio da adesão aos progressos mais recentes da psicologia infantil e ao escolanovismo sucumbiram à lógica do sistema estatal. Ainda assim, reconhece que o mito da ciência moderna trazia a novidade e o argumento central da crítica aos padrões convencionais da política e da administração pública, encontrando ressonância entre os intelectuais e homens ilustrados do Brasil à época (Bomeny, 1993: 25-27). Segundo Bomeny (1993: 28), foi desse credenciamento típico, conferido pela ciência e distinto da autoridade política tradicional, que Fernando de Azevedo se beneficiou ao dirigir a mais importante de todas as reformas do ensino do país antes de ser posto à prova pelo novo regime.

Nessa mesma direção, Milton Lahuerta (1997: 106) percebeu na ênfase pedagógica das posições de um Fernando de Azevedo, de um Anísio Teixeira, de um Mário de Andrade e de um Villa Lobos a vitória de um pensamento que, estatista e permeado de referências modernistas, oferecia aos intelectuais uma concepção de mundo e um caminho para realizá-las. Sob um ângulo de visão genericamente modernista, todos eles recolocaram, com muita força, a preocupação com o nacional e com o tema do popular, buscando na educação um meio de reformar a sociedade, criar técnicos e renovar as elites. De modo semelhante ao de Bomeny, Lahuerta (1997: 107) conclui que a adesão à mudança vai sendo paulatinamente frustrada pelo caráter restaurador do processo inaugurado em $1930 \mathrm{e}$, ao ser chamada a participar do processo, a intelectualidade passa a constituir um novo bloco de poder. Conforme seu entendimento, a urdidura política dos anos 30 realiza a fusão entre modernidade e projeto nacional de maneira autoritária e útil à consumação de um certo sentido de missão que se entranha à condição do intelectual egresso dos debates dos anos 20 (cf. Lahuerta, 1997: 106).

Em alguma medida, os diversos conjuntos de pesquisa sobre a chamada reforma Fernando de Azevedo que abordei aqui testemunham a permanência da opção pelos termos moderno e modernidade para definir os processos de mudança 


\section{André Luiz Paulilo}

então observados. A realização coletiva das últimas duas décadas é considerável, mas o movimento não é unívoco. As abordagens praticadas que focam as apostas reformistas de Azevedo no Distrito Federal entre 1927 e 1930 sob a rubrica do moderno e da modernidade são variadas e, a rigor, exploram novos temas com o auxílio de novos conceitos.

De qualquer forma, elas são o exemplo de uma historiografia voltada para o estudo da mudança e da inovação no ensino. Não obstante estar aí o principal tópico à qual recorreu a geração de educadores envolvida com as reformas do ensino nos anos 20, com o objetivo de persuadir os outros que o seu período ou sua geração foi especial, a atual série de pesquisas a esse respeito tem contribuído para a compreensão da memória do movimento educacional. Depois da salutar reação à demarcação do campo educacional realizada pela narrativa de Fernando de Azevedo em $A$ cultura brasileira, a modernidade que a historiografia da educação ainda confere hoje à reforma de 1928 vem sendo entendida para além do campo educacional. Como procurei sugerir aqui, hoje não são incomuns as abordagens culturais dos empreendimentos reformistas dos anos 20, incluindo a relação entre a escola e as transformações urbanísticas e sociais da época.

Ao pretender dar aos leitores uma ideia da variedade de estudos sobre a reforma Fernando de Azevedo, da qual um dos motes é o que se acredita ser moderno, considerei que há distinções a fazer acerca do emprego de uma noção desse tipo. Tendo em vista que os termos moderno e modernidade não são noções convenientes para a descrição objetiva de um processo de mudança, entendi que a recorrência com que a historiografia da educação se valeu dessas expressões para analisar a dinâmica da tentativa escolanovista de afirmar-se como uma ruptura com a tradição mereceria uma atenção mais detida.

No caso da reforma Fernando de Azevedo, o conjunto de conexões possíveis de explorar a partir dessa opção da abordagem é particularmente visível. Não só os termos Escola Nova e modernidade estão ligados de mais de um modo, há hoje uma séria tentativa de se compreender os vínculos entre essa reforma do ensino e a urbanização da cidade do Rio de Janeiro, os meios de comunicação em massa e algumas das representações sociais de então. A reforma do ensino de 1928 também foi discutida do ponto de vista político, focalizando-se a contradição entre o seu apelo modernizador e a velha política a que servia ou o tipo de poder moderno que credenciava as práticas da Diretoria de Ensino. Reunidos, esses estudos e discussões atestam a utilidade de esquemas perceptivos de análise, mas nesse caso é necessário, sobretudo, distinguir o que é uma perspectiva de compreensão histórica daquilo que é uma hipérbole à qual recorreu toda uma geração de educadores para persuadir-nos da importância das suas realizações ou do que não passa de uma mera projeção dos nossos valores sobre o passado. 
ABDALA, Rachel Duarte. A fotografia além da ilustração: Malta e Nicolas construindo imagens da reforma educacional no Distrito Federal (1927-1930). In: VIDAL, Diana Gonçalves (org.). Educação e reforma: o Rio de faneiro nos anos 1920-1930. Belo Horizonte: Argvmentvm, 2008.

-A fotografia além da ilustração: Malta e Nicolas construindo imagens da reforma educacional no Distrito Federal (1927-1930). Dissertação (Mestrado em Educação). Universidade de São Paulo, São Paulo, 2002.

ACCÁCIO, Liéte de Oliveira. 2004. A Escola Normal do Rio de Janeiro: a construção da profissão docente. In: PÔRTO JR., Gilson (org). Raízes da modernidade: o pensamento de Fernando de Azevedo. Brasília: Ativa, 2004, p. 123-130.

. Docentes e catedráticos: os concursos para professor da Escola Normal do Distrito Federal (1928-1930). Tese (Doutorado em Educação) - Universidade de São Paulo, 2001.

- Instituto de Educação do Rio de Faneiro: a história da formação do professor primário (1927-1937). Dissertação (Mestrado em Educação) - Universidade Federal do Rio de Janeiro, Rio de Janeiro, 1993.

ALVES, Cláudia Costa. Os resumos das comunicações e as possibilidades esboçadas no II Congresso Luso-Brasileiro de História da Educação. In: CATANI, Denice \& SOUZA, Cynthia Pereira de. Práticas educativas, culturas escolares, profissão docente. São Paulo: Escrituras, 1998.

AZEVEDO, Fernando de. A cultura brasileira. Rio de Janeiro: Serviço Gráfico do
Instituto Brasileiro de Geografia e Estatística, 1943.

BOMENY, Helena. Novos talentos, vícios antigos: os renovadores e a política educacional. Estudos Históricos, Rio de Janeiro, vol. 6, n. ${ }^{\circ} 11,1993$, p. 24-39.

et. al. Tempos de Capanema. Rio de Janeiro: Paz e Terra; São Paulo: Edusp, 1984.

BONTEMPI JR., Bruno. História da educação brasileira: o terreno do consenso. In: FREITAS, Marcos Cezar de (org.). $\mathrm{Me}$ mória intelectual da educação brasileira. Bragança Paulista: EDUSF, 1999, p. 87-100.

- História da educação brasileira: o terreno do consenso. Dissertação (Mestrado em Educação) - Pontifícia Universidade Católica de São Paulo, São Paulo, 1995.

CARVALHO, Marta Maria Chagas de. Reformas da instrução pública. In: LOPES, Eliane Marta Teixeira; FARIA FILHO, Luciano Mendes \& VEIGA, Cynthia Greive (orgs.). 500 anos de educação no Brasil. Belo Horizonte: Autêntica, 2000, p. 224-251.

O território do consenso e a demarcação do perigo: política e memória do debate educacional dos anos 1930. In: FREITAS, Marcos Cézar de (org.). Memória intelectual da educação brasileira. Bragança Paulista: EDUSF, 1999, p. 17-30.

Molde nacional e forma cívica: higiene, moral e trabalho no projeto da Associação Brasileira de Educação (1924-1931). Bragança Paulista: Edusf, 1998.

O novo, o velho, o perigoso: relendo A Cultura Brasileira. Cadernos de Pesquisa, n. ${ }^{\circ} 71,1989$, p. 29-35. 
- Notas para reavaliação do movimento educacional brasileiro (19201930). Cadernos de Pesquisa, n. ${ }^{\circ}$ 66, 1988, p. 4-11.

\& NUNES, Clarice. Historiografia da educação e fontes. Cadernos ANPEd. n. ${ }^{\circ}$ 05, 1993, p. 7-64.

CATANI, Denice \& FARIA FILHO, Luciano Mendes de. Um lugar de produção e a produção de um lugar: a história e a historiografia divulgadas no GT História da Educação da ANPEd (1985-200). Revista Brasileira de Educação, n. ${ }^{\circ}$ 19, 2002, p. 113128.

CURY, Carlos Roberto Jamil. Ideologia e educação brasileira: católicos e liberais. São Paulo: Cortez Autores Associados, 1978 (Coleção Educação Contemporânea).

FARIA FILHO, Luciano Mendes de \& VIDAL, Diana Gonçalves. As lentes $d a$ história: estudos de história e historiografia da educação no Brasil. Campinas: Autores Associados, 2005.

GHIRALDELLI Jr., Paulo. Educação e movimento operário. São Paulo: Cortez, 1986.

HANNA MATTE, Cecília. Tempos modernos na escola: os anos 30 e a racionalização da educação brasileira. Bauru: Edusc; Brasília: INEP, 2002.

HILSDORF, Maria Lúcia Spedo. História da educação brasileira: leituras. São Paulo: Pioneira Thomson Learning, 2003.

LAHUERTA, Milton. Os intelectuais e os anos 20: moderno, modernista, modernização. In: LORENZO, Helena Carvalho de \& COSTA, Wilma Peres da (orgs.). $A$ década de 1920 e as origens do Brasil moderno. São Paulo: Unesp, 1997, p. 93-114.

LOPES, Sonia de Castro. Oficina de Mestres: história, memória e silêncio sobre a Escola de Professores do Instituto de Educação do Rio de Faneiro (1932-1939). Rio de Janeiro: DP\&A/Faperj, 2006.
MONARCHA, Carlos. $A$ reinvenção $d a$ cidade e da multidão: dimensões da modernidade brasileira - a Escola Nova. São Paulo: Cortes/Autores Associados, 1989.

NAGLE, Jorge. A educação na Primeira República. In: FAUSTO, Boris (org.). História Geral da Civilização Brasileira. Tomo III, vol. 2. São Paulo: Difel, 1977, p. 261-291.

Educação e sociedade na Primeira República. São Paulo: EPU, Edusp, 1974.

NUNES, Clarice. Cultura escolar, política educacional e espaço urbano. A modernidade pedagógica na cidade do Rio de Janeiro. In: FERNANDES, Rogério \& ADÃO, Aurea (orgs.). Leitura e escrita em Portugal e no Brasil 1500-1970: actas do $1^{\circ}$ Congresso Luso-Brasileiro de História da Educação. vol. 1. Porto: Sociedade Portuguesa de Ciências da Educação, 1998, p. 273-280.

. Cultura escolar, modernidade pedagógica e política educacional no espaço urbano carioca. In: HERSCHMANN, Micael; KROPF, Simone \& NUNES, Clarice. Missionários do progresso: médicos, engenheiros e educadores no Rio de Faneiro 1870-1937. Rio de Janeiro: Diadorim, 1996, p. 155-224.

- A escola nova no Brasil: do estado da arte à arte do estudo. In: GVIRTZ, Silvina. Escuela Nueva en Argentina y Brasil. Buenos Aires: Miño y Dávila Editores, 1995, p. 13-39.

. A escola reinventa a cidade. In: HERSCHMANN, Micael \& PEREIRA, Carlos Alberto Messeder (orgs.). A invenção do Brasil moderno: medicina, educação e engenharia nos anos 20-30. Rio de Janeiro: Rocco, 1994, p. 180-201.

- A escola redescobre a cidade: reinterpretação da modernidade pedagógica no espaço urbano carioca (1910-1935). Tese de Concurso para Professor Titular em História da Educação - Departamento de 
Fundamentos Pedagógicos, Faculdade de Educação, Universidade Federal Fluminense, Niterói, 1993.

. História da educação brasileira: novas abordagens de velhos objetos. Teoria e Educação, n. ${ }^{\mathrm{O}}$ 6, 1992, p. 151-181.

OLIVEIRA, Beatriz Santos de. Modernidade oficial: a arquitetura das escolas públicas do Distrito Federal (1928-1940). Dissertação (Mestrado em Educação) Faculdade de Arquitetura e Urbanismo, Universidade de São Paulo, São Paulo, 1991.

PAIVA, Vanilda Pereira. Educação popular e educação de adultos: contribuição à história da educação brasileira. São Paulo: Loyola, 1973.

ROCHA, Marlos Bessa Mendes da. Matrizes da modernidade republicana: cultura política e pensamento educacional no Brasil. Campinas: Autores Associados; Brasília: Plano, 2004.

RODRIGUES, Rosane Nunes. A escolarização dos saberes domésticos e as múltiplas representações de feminino. Rio de Janeiro - 1920 e 1930. In: VIDAL, Diana Gonçalves (org.). Educação e reforma: o Rio de Faneiro nos anos 1920-1930. Belo Horizonte: Argvmentvm, 2008, p. 59-76.

\& VIDAL, Diana Gonçalves. A casa, a escola ou o trabalho: o Manifesto e a profissionalização feminina no Rio de Janeiro (1920-30). In: XAVIER, Maria do Carmo. Manifesto dos Pioneiros da Educação: um legado educacional em debate. Rio de Janeiro: FGV, 2004, p. 89-112.

\footnotetext{
- Representações de feminino e educação profissional doméstica (Rio de faneiro 1920 e 1930). Dissertação (Mestrado em Educação) - Faculdade de Educação, Universidade de São Paulo, São Paulo, 2002.

SAVIANI, Dermeval. Escola e democracia. São Paulo: Cortez; Campinas: Autores Associados, 1983.
}

SILVA, José Cláudio Sooma. A reforma Fernando de Azevedo: tempos escolares e sociais (Rio de Faneiro, 1927-1930). Dissertação (Mestrado em Educação) - Faculdade de Educação, Universidade de São Paulo, São Paulo, 2004.

VIDAL, Diana Gonçalves et. al. 2005. História da Educação no Estado de São Paulo: a configuração do campo e a produção atual (1943-2003). In: GONDRA, José Gonçalves (org.). Pesquisa em história da educação no Brasil. Rio de Janeiro: DP\&A, 2005, p. 157-219.

- O exercício disciplinado do olhar: livoros, leituras e práticas de formação docente no Instituto de Educação do Distrito Federal (1932-1937). Bragança Paulista: EDUSF, 2001.

- Educação sexual: produção de
identidades de gênero na década de 1930. In:
SOUSA, Cynthia Pereira de. História da
educação: processos, práticas e saberes. São
Paulo: Escrituras, 1998, p. 53-74. . A "educação doméstica" e a reforma da instrução pública no Distrito Federal. Cadernos de Pesquisa, São Paulo: Fundação Carlos Chagas, n. ${ }^{\circ}$ 99, 1996, p. 30-35.

\footnotetext{
. Nacionalismo e tradição na prática discursiva de Fernando de Azevedo. Revista do Instituto de Estudos Brasileiros. n. ${ }^{\circ}$ 37, 1994, p. 35-52.
}

WARDE, Miriam Jorge. Anotações para uma historiografia da educação brasileira. Em Aberto. Brasília, n. ${ }^{\circ}$ 23, 1984, p. 1-6.

XAVIER, Libânia Nacif. 2001. "Particularidades de um campo disciplinar em consolidação: balanço do I Congresso Brasileiro de História da Educação (RJ/2000)". In: SBHE (org.). Educação no Brasil:história e historiografia. Campinas: Autores Associados; São Paulo: SBHE, 2001,p. 217-234.

O Brasil como laboratório: educação e ciências no projeto dos Centros Brasileiros de Pesquisas Educacionais CBPE/INEP/MEC (1950-1960). Bragança Paulista: EDUSF, 1999. 


\section{André Luiz Paulilo}

\section{Resumo}

$\mathrm{O}$ artigo trata da historiografia do movimento educacional brasileiro entre 1920 e 1930, especialmente dos estudos acerca da reforma Fernando de Azevedo na cidade do Rio de Janeiro. O primeiro ponto discutido é a relevância e a aplicabilidade da ideia de modernidade para definir o período. Sugere que essa ideia foi marcada por transformações na historiografia do movimento educacional nos anos 20 e 30 . O segundo é o significado da ideia de modernidade para a organização das atuais interpretações sobre o movimento educacional no Brasil. Por fim, é abordada a mudança fundamental da sensibilidade historiográfica dos estudos sobre a reforma Fernando de Azevedo.

Palavras-chave: história da educação, reforma Fernando de Azevedo, movimento educacional brasileiro (1920-1930), modernidade educacional.

\footnotetext{
Abstract

This paper focuses the historiography of the Brazilian educational movement between 1920 and 1930, especially in studies about the reform Fernando de Azevedo from Rio de Janeiro city. The first point discussed is the relevance and applicability of the idea of modernity to definite the period. It suggests that this idea was marked by the transformation in the educational movement historiography. The second point refers to the meaning of the idea of modernity to the organization of the interpretation about the educational movement from Brazil. Finally, the text examines the major change in historiographical sensibility of the studies about the reform Fernando de Azevedo.

Key words: history of education, reform Fernando de Azevedo, Brazilian educational movement (1920-1930), educational modernity.
}

\section{Résumé}

Larticle porte sur l'historiographie du mouvement éducatif brésilien entre 1920 et 1930, en particulier les études de la réforme Fernando de Azevedo dans la capital du Brésil. La première question se rapporte à l'importance et l'applicabilité de l'idée de modernité par définir le période.

On suggère que cette idée fut marquée par changements dans la historiographie du mouvement éducatif des années 20 et 30 .

La deuxième question se refere au sens de l'idée de modernité pour l'organization des récentes interpretations sur le mouvement educational au Brésil. Finalement, on aborde le changement fondamental de 
la sensibilité historiographique des études sur la réforme Fernando de Azevedo.

Mots-clés: histoire de l'education, réforme Fernando de Azevedo, mouvement éducatif brésilien (1920-1930, modernité éducative. 